\title{
Reconhecimento de direitos e significados de infância entre crianças
}

\author{
Gilberto Lima dos Santos \\ Antonio Marcos Chaves
}

\section{Resumo}

Este estudo teve como objetivos saber se as crianças reconhecem alguns dos seus direitos, quais conhecimentos sobre esses direitos são compartilhados e quais os significados de infância que esses compartilhamentos indicam. É um estudo comparativo, orientado pela Psicologia Sócio-Histórica, cujos dados foram analisados qualitativamente. Os participantes foram vinte e uma crianças, com idade entre nove e onze anos. Sete crianças eram estudantes de uma escola particular urbana, sete, de uma escola pública urbana e as outras sete, de uma escola pública rural. Foi utilizada a técnica da entrevista individual semiestruturada, baseada na apresentação de imagens impressas. Os direitos mais reconhecidos pelas crianças foram referentes à alimentação, à educação e ao brincar, que são direitos entrelaçados a significados de infância mais amplamente compartilhados. Quanto à proibição do trabalho infantil e ao direito à inviolabilidade da integridade física, elas apresentaram compartilhamentos divergentes.

Palavras-chave: Direitos da criança, infância, significados.

\section{Acknowledgement of rights and meanings of childhood among children}

\begin{abstract}
This study intended to investigate whether children acknowledge some of their rights, which knowledge about their rights are shared among them and what are the meanings of childhood these sharings indicate. It is a comparative study guided by the social-historical psychological approach of which data were analyzed qualitatively. The participants consisted of 21 children, aging from 9 to 11 years old. Seven children were students in a private urban school, seven studied in a public urban school, and seven studied in a public school located in the countryside. The individual semi-structured interview technique was used, based on the presentation of printed images. Rights referring food and nourishment, education and playing were the most acknowledged by children. Concerning to the interdicted childish working or the right referring inviolability of the physical integrity, they demonstrated different ways of sharing.
\end{abstract}

Keywords: Children's rights, childhood, meanings.

\section{Reconocer derechos y significados de infancia entre niños}

\section{Resumen}

Este estudio tuvo como objetivos saber si los niños reconocen algunos de sus derechos, cuál es el conocimiento sobre esos derechos que son compartidos y cuáles son los significados de infancia que ese compartir indica. Es un estudio comparativo, orientado por la Psicología SocioHistórica, cuyos datos se analizaron cualitativamente. Los participantes fueron veintiún niños, con edades entre nueve y once años. Siete niños eran estudiantes de una escuela particular urbana, siete de una escuela pública urbana y siete de una escuela pública rural. Se utilizó la técnica de entrevista individual semi-estructurada, con base en presentación de imágenes impresas. Los derechos más reconocidos por los niños fueron referentes a la alimentación, a la educación y a jugar, que son derechos entrelazados a significados de infancia más ampliamente compartidos. Referente a la prohibición del trabajo infantil y al derecho a la inviolabilidad de la integridad física, los niños presentaron formas de compartir divergentes.

Palabras-clave: Derechos del niño, infancia, significados. 


\section{Introdução}

Realizamos um estudo, ao longo de 2006, procurando saber se as crianças reconhecem alguns dos seus direitos, quais conhecimentos sobre esses direitos são compartilhados e quais os significados de infância que esses compartiIhamentos indicam. É sobre essa pesquisa que trataremos neste relato.

Os estudos que encontramos nas bases de dados, no campo da Psicologia, realizados no período de 1996 a 2004, apenas indiretamente referiam-se aos direitos das crianças. Esses estudos focalizavam os processos cognitivos (Alves, 1993; A. M. V. Pinheiro, 1995), a afetividade (Melchiori \& Alves, 2000), as diferenças individuais (Fiamenghi, Bressan, \& Porto, 2003; Keller, 1998), o trabalho infantil (Hurtado, 2002), o abuso sexual (Alvarenga, Julião \& Silva, 1998; França Junior, 2003), a delinquência (Assis \& Constantino, 2001), a dependência química (Matos, Van der Put, \& Ferreira, 1998) etc.

Não encontramos, nas bases de dados, trabalhos sobre os direitos das crianças que considerassem o ponto de vista das próprias crianças. Os trabalhos encontrados eram centrados no ponto de vista de adultos ou, no máximo, no ponto de vista de adolescentes, a exemplo de Cardoso (1998), Menin (2000), Molinari (2001), A. A. A. Pinheiro (2004) e Teixeira (2001).

A questão que nos colocávamos era a de saber se as crianças estariam em sintonia com as informações circulantes sobre os seus direitos, principalmente em função do tempo transcorrido desde a realização da Convenção das Nações Unidas sobre os Direitos das Crianças (UNICEF Brasil, 2007), em 1989, e desde a edição do Estatuto da Criança e do Adolescente (Brasil, 1995), em 1990. Porém, levávamos em consideração que, se os conhecimentos estão disponíveis para todos, nem todos têm possibilidades de acessá-los. A acessibilidade desses conhecimentos depende diretamente das condições concretas de vida de cada indivíduo. E a pauperização de amplos contingentes populacionais certamente abre um fosso enorme, no Brasil, entre a maioria dos indivíduos dos segmentos sociais menos favorecidos e os meios de acesso ao conhecimento. Essa distância é mais acentuada, ainda, em se tratando das novas tecnologias e do mundo digital.

Nesse sentido, para o acesso ao conhecimento, configuram-se, também, como fundamentais, a existência de escola, a qualidade do ensino e o nível de escolarização do sujeito. O sujeito precisa ser instrumentalizado através do desenvolvimento de habilidades específicas, sem as quais as informações e os conhecimentos Ihe escapam. Entretanto, conforme assinala Gentili (1995), a lógica do consumo permeia a difusão de informação e a educação, tanto no sentido lato, dos processos de socialização, quanto no sentido estrito, da escolarização. Em função de suas estratégias mercantilizantes, o neoliberalismo empenha-se em destituir a educação do seu caráter político, transformando-a em mercadoria. $\mathrm{E}$, como mercadoria, a educação apresenta-se no mundo dos consumidores com distintos valores e qualidades.
Segundo Gentili (1995), a educação de qualidade torna-se, num dos extremos, direito de propriedade de alguns consumidores, aptos economicamente a possuí-la. Esses consumidores podem competir no mercado de trabalho, logicamente, com melhores chances de emprego e melhores níveis de inserção. No outro extremo, torna-se legítimo que a maioria dos supostos consumidores seja excluída da possibilidade de usufruí-la. Isso porque a perspectiva neoliberal "reconhece que o Estado pouco ou nada pode fazer para melhorar a qualidade educacional sem produzir o efeito perverso contrário: nivelar por baixo" (p.246). Portanto, em se tratando das maiorias excluídas, a educação neoliberal para o emprego "não é outra coisa senão a educação para o desemprego e a marginalidade" (p.249).

Compartilhamos o entendimento de que a sociedade atual tem reservado à criança, prioritariamente, o espaço do consumo. Neste espaço, são endereçadas à criança múltiplas ofertas de bens e serviços. É com base no direito e no dever de consumir que crianças, adolescentes e adultos tendem à igualdade. Pode-se mesmo dizer que, desse modo, a criança é compelida a um tipo de exercício da cidadania, como afirma Salles (2005). Esta autora salienta que "as coisas e os objetos que possuímos demarcam relações sociais, definem o estilo pessoal, hierarquizam e discriminam grupos" (p.39). Como o acesso aos bens de consumo depende da condição social de cada indivíduo, quando olhamos para as crianças, encontramos, então, ao menos duas infâncias: uma com maior poder aquisitivo, que transita pelo espaço do consumo com facilidade, com desenvoltura, e outra que dele é excluída.

Ainda que uma ênfase excessiva no direito de consumir seja direcionada às crianças, esse direito é parte integrante de uma totalidade que reconhecemos hoje como cidadania. Domingues (2002) aponta o direito como sendo "uma das principais expressões da cidadania na modernidade" (p.141). E Marshall (1967) analisa o conceito de cidadania como sendo composto por três dimensões: civil, política e social. A dimensão civil comporta os direitos individuais à liberdade. À dimensão política vincula-se o "direito de participar no exercício do poder político, como um membro de um organismo investido da autoridade política ou como um eleitor dos membros de tal organismo" (p.63). A dimensão social apresenta-se como uma gradação, em termos de possibilidades, que vai do "direito a um mínimo de bem-estar econômico e segurança ao direito de participar" integralmente da vida social, de acordo com os padrões vigentes (p.63).

Marshall (1967) atribui a cada uma das dimensões do conceito de cidadania um período de formação diferente. Os direitos civis teriam sido formados no século XVIII, os direitos políticos, no século XIX e os direitos sociais, no século XX. De acordo com Bobbio (1992), o reconhecimento dos direitos sociais possibilita que novos sujeitos de direito surjam, a exemplo do doente mental, do idoso, da mulher, da criança etc.

Entendemos, com Bobbio (1992), que o nascimento e o crescimento dos direitos humanos e as transformações da sociedade são intimamente associados. Em se tratando dos 
direitos das crianças, podemos notar a estreita vinculação que há entre estes e o desenvolvimento da concepção de infância. Como afirmam Chaves, Borrione e Mesquita (2004), foi excluindo as crianças do mundo adulto que se efetivou a criação da infância. Sua delimitação evoluiu, incorporando a ideia de inocência, de fragilidade, de certa incapacidade, e evocando a necessidade de proteção e provisão. De acordo com Salles (2005), o desenvolvimento da concepção de infância conferiu às crianças, na modernidade, o status de dependência e a isenção de responsabilidade em termos jurídicos, políticos e emocionais.

Portanto, podemos pensar que tratar sobre os direitos das crianças ou, mais especificamente, sobre os direitos que as crianças reconhecem como seus, remete à necessidade de compreender o processo de construção da subjetividade ou, em outros termos, compreender a relação que se estabelece entre o indivíduo e a sua cultura. Mesmo porque a concepção de infância muda ao longo da história, conforme sugere Ariès (1981), e apresenta características distintivas de cultura para cultura, de contexto para contexto, cambiando, assim, os papéis desempenhados pelas crianças e sua inserção nas práticas sociais (Kramer, 2003).

Os processos cognitivos, emocionais, motivacionais e comportamentais das pessoas ganham forma através do engajamento num mundo cultural. Então, a diversidade psicológica é um inevitável resultado da coordenação de respostas pessoais com os prevalentes sistemas de significados e práticas culturais, historicamente criados e diversamente organizados (Fiske, Kitayama, Markus \& Nisbett, 1998).

Sendo assim, a realidade coletiva é composta de ideias culturais nucleares juntamente com fatores ecológicos, econômicos e sociopolíticos, que são associados a um conjunto de significados culturais, práticas, normas e instituições sociais. Juntos, estes constituem a matriz em que são incorporadas as intenções, regras, práticas e atividades através das quais as pessoas vivem as suas vidas. Neste sentido, o engajamento social, num mundo culturalmente organizado, não é algo que os humanos podem voluntariamente escolher fazer, mas algo que devem fazer para funcionar como humanos (Fiske e cols., 1998).

Essas aptidões tipicamente humanas são formadas ao longo da vida através do processo de apropriação da cultura. Esse processo ocorre à medida que o indivíduo estabelece relações com os objetos e fenômenos criados pelas gerações anteriores. Essa relação, por sua vez, torna-se viável apenas através de um processo de comunicação com outros seres humanos (Leontiev, 1978). O processo de comunicação com outros seres humanos é mediador. Mas, ao mesmo tempo, é mediado, pois essa comunicação só se efetiva através da linguagem. A esse respeito, Bronckart (1999) indica que a linguagem constitui um aspecto primordial das práticas sociais, possibilitando o processo histórico de socialização que forma as características tipicamente humanas.

É importante assinalar que, segundo Vygotsky (2000), os significados das palavras mudam ao longo do desenvolvimento do indivíduo. Além disso, considerando que a fonte de significados para o indivíduo é o grupo cultural de que parti- cipa (Oliveira, 1992), torna-se importante, também, observar as indicações feitas por Miller (1996). A primeira indicação desse autor é que, no âmbito da população, os significados variam nos subgrupos. Isso ocorre porque o compartilhamento não é homogêneo. Os subgrupos acessam os significados de modo diferenciado. A segunda indicação é que os significados mudam enquanto são difundidos em unidades sociais como famílias, escolas, comunidades ou grupos distinguidos pelo status socioeconômico. Portanto, o acesso a esses significados é mediado pela linguagem e depende das habilidades que o sujeito desenvolve neste campo, ou seja, depende de suas condições concretas de existência.

\section{Método}

Neste estudo, procuramos comparar as informações fornecidas por crianças, situadas em três diferentes tipos de escola. É um estudo qualitativo, orientado pela Psicologia Sócio-Histórica. Sendo assim, concebemos a noção de significados como os conhecimentos compartilhados pelas crianças sobre os seus direitos. Segundo Molon (2003), o significado acompanha a palavra (ainda que não se restrinja a ela), é convencional, dicionarizado. Consideramos a importância, também, de verificar se os significados são expressos, pelas crianças, predominantemente através de conceitos espontâneos ou de conceitos científicos.

Os conceitos espontâneos, ou cotidianos, são assistemáticos, carecem de relações de generalidade desenvolvidas (Vygotsky, 2000). São pensamentos situacionais, concretos, baseados na experiência prática do sujeito, compostos predominantemente por elementos visuais (Luria, 1990). Os conceitos científicos, por sua vez, resultam principalmente da experiência da criança na escola, são sistemáticos e abstratos (Vygotsky, 2000). Portanto, são pensamentos lógicos, teóricos, categoriais e generalizantes, que classificam objetos por variadas propriedades (Luria, 1990).

Tomando o Estatuto da Criança e do Adolescente (Brasil, 1995) como referência, consideramos criança o indivíduo com idade entre zero e doze anos incompletos. Quanto aos direitos das crianças, compreendemo-los como os direitos fundamentais à dignidade do ser humano.

Os artigos do Estatuto da Criança e do Adolescente mais diretamente implicados neste estudo são os seguintes:

Art. $4^{\circ}$ - sintetiza os direitos fundamentais (relativos à vida, à saúde, à alimentação, à educação, ao esporte, ao lazer, à profissionalização, à cultura, à dignidade, ao respeito, à liberdade e à convivência familiar e comunitária) e atribui responsabilidade à família, à comunidade, à sociedade em geral e ao poder público pela sua efetivação, assegurando-a como absoluta prioridade;

Art. $5^{\circ}$ - condena qualquer atentado aos direitos fundamentais da criança e do adolescente (discriminação, exploração, violência, crueldade e opressão) e prevê punição na forma da lei; 
Art. $7^{\circ}$ - especifica o direito à proteção à vida e à saúde, relacionando-o ao nascimento e ao desenvolvimento sadio e harmonioso e a condições dignas de existência;

Art. 15 - focaliza o direito à liberdade, ao respeito e à dignidade;

Art. 16 - caracteriza o direito à liberdade, relacionando-o a: ir, vir e estar nos logradouros públicos e espaços comunitários (ressalvadas as restrições legais); opinião e expressão; crença e culto religioso; brincar, praticar esportes e divertir-se; participar da vida familiar e comunitária (sem discriminação); participar da vida política (na forma da lei); buscar refúgio, auxílio e orientação;

Art. 17 - caracteriza o direito ao respeito como inviolabilidade da integridade física, psíquica e moral, o que inclui a preservação da imagem, da identidade, da autonomia, dos valores, ideias e crenças, dos espaços e objetos pessoais;

Art. 18 - caracteriza o direito à dignidade como isenção a qualquer tratamento desumano, violento, aterrorizante, vexatório ou constrangedor;

Art. 53 - afirma o direito à educação e sua estreita relação com o pleno desenvolvimento pessoal e com o preparo para o exercício da cidadania e para a qualificação ao trabalho;

Art. 60 - proíbe qualquer trabalho aos menores de catorze anos de idade, exceto na condição de aprendiz.

\section{Participantes}

Os participantes foram vinte e uma crianças, com idade na faixa de nove a onze anos, distribuídas em três escolas diferentes no município de Senhor do Bonfim, Estado da Bahia. Sete dessas crianças eram estudantes de uma escola pública rural, outras sete, de uma escola pública urbana e mais sete, de uma escola particular urbana. Foi solicitada a autorização dos pais dos participantes, através da assinatura do Termo de Consentimento Livre e Esclarecido, enviado a eles pela própria Escola.

O município de Senhor do Bonfim, distante 386 km de Salvador, está localizado no semiárido baiano, ao norte do Estado. A escola particular fica situada no centro da cidade, a escola pública urbana, em um bairro periférico e a escola rural, em um povoado rural, distante da cidade cerca de $5 \mathrm{~km}$. O município dispõe de Conselho Tutelar, mas, até a época da coleta de dados, este não havia ainda desenvolvido qualquer ação visando à difusão do Estatuto da Criança e do Adolescente nas escolas, segundo informações que obtivemos nas próprias escolas.

\section{Coleta de dados}

Foi utilizada a técnica da entrevista individual semiestruturada a partir da apresentação de cinco imagens impressas. As imagens são desenhos que retratam cenas protagonizadas por crianças. Cada cena sugere o exercício ou a violação de um direito específico. A cena $n^{\circ} .4$ (Figura
4) constitui uma exceção, pois caracteriza a violação de uma proibição constitucional. O Art. 227 da Constituição Federal do Brasil proíbe qualquer trabalho a menores de 16 anos de idade, exceto na condição de aprendiz, a partir de 14 anos. Esta proibição reaparece no Art. 60 do Estatuto da Criança e do Adolescente. Portanto, através da cena $n^{\circ} .4$ (Figura 4), procuramos averiguar se as crianças reconheciam essa proibição, pois, a despeito destes dispositivos legais, sabese que, no Brasil, especialmente na região Nordeste, ainda há a utilização do trabalho infantil nas atividades agropecuárias de subsistência e na faina doméstica.

As cenas são estreitamente relacionadas aos direitos preconizados pelo Estatuto da Criança e do Adolescente (ECA), conforme segue:

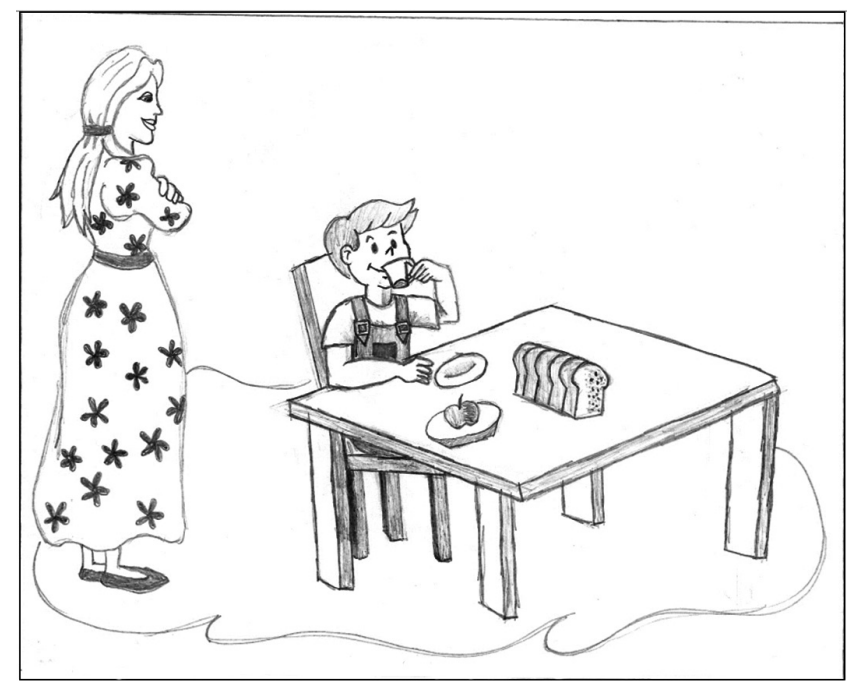

Figura 1. Direito à alimentação (conforme artigos $4^{\circ} \mathrm{e} 7^{\circ}$ )

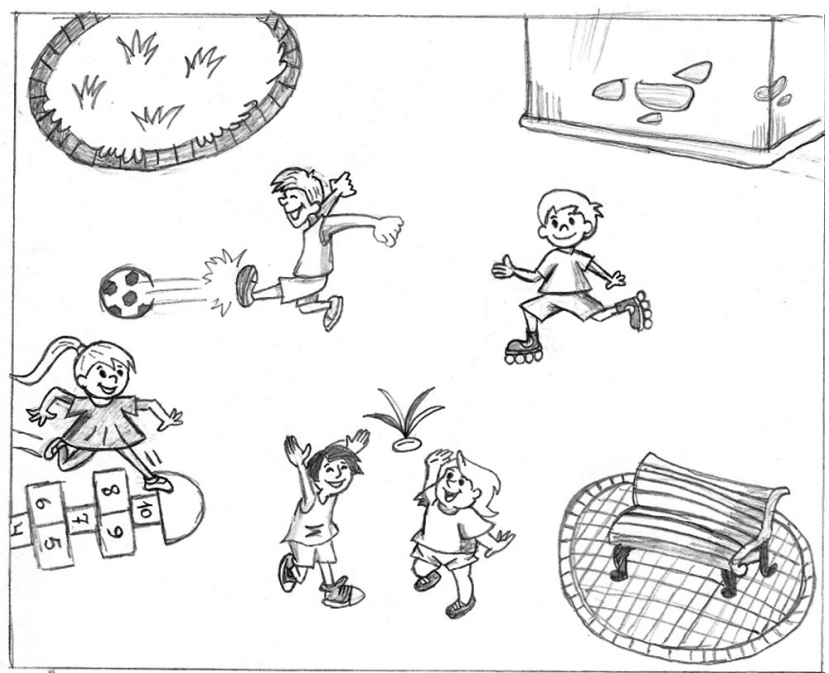

Figura 2. Direito de brincar (conforme artigos $4^{\circ}, 15$ e 16) 


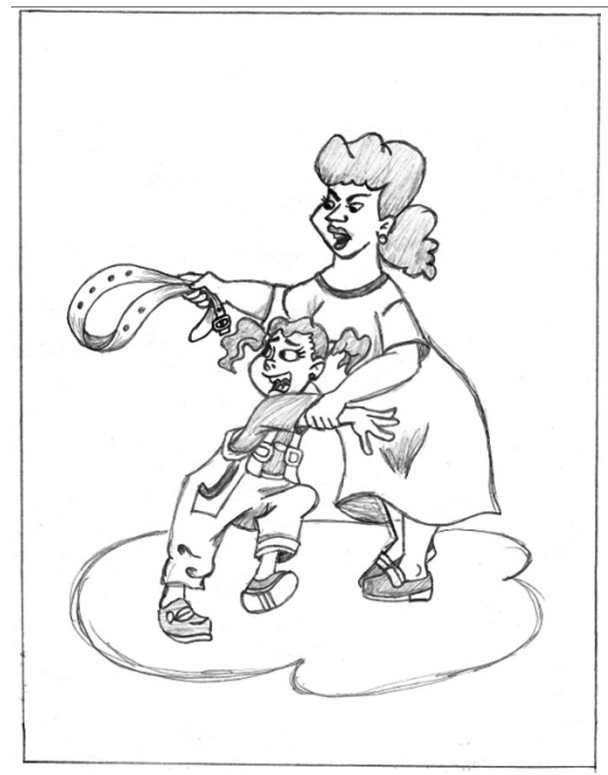

Figura 3. Direito à inviolabilidade da integridade física (conforme artigos $5^{\circ}, 17$ e 18)

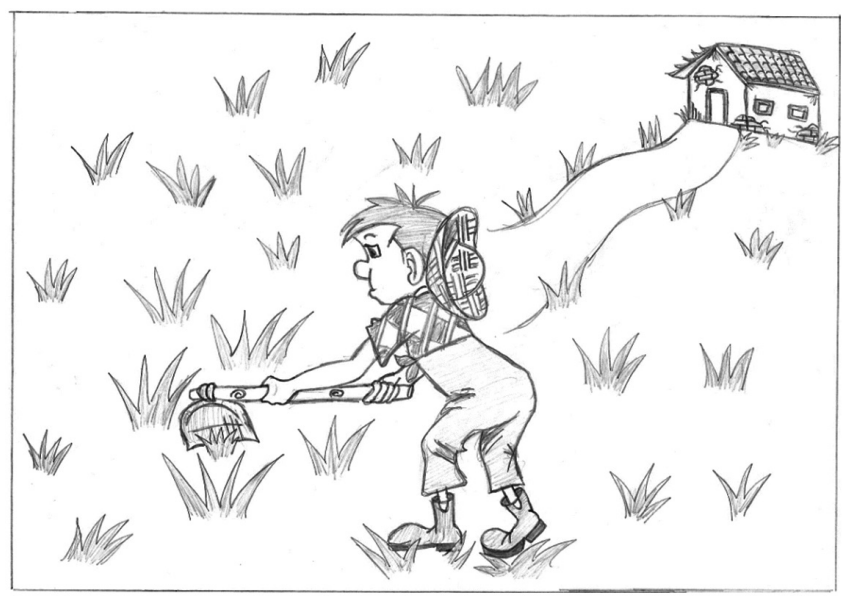

Figura 4. Proibição do trabalho (conforme artigos $5^{\circ}, 17$ e 60)

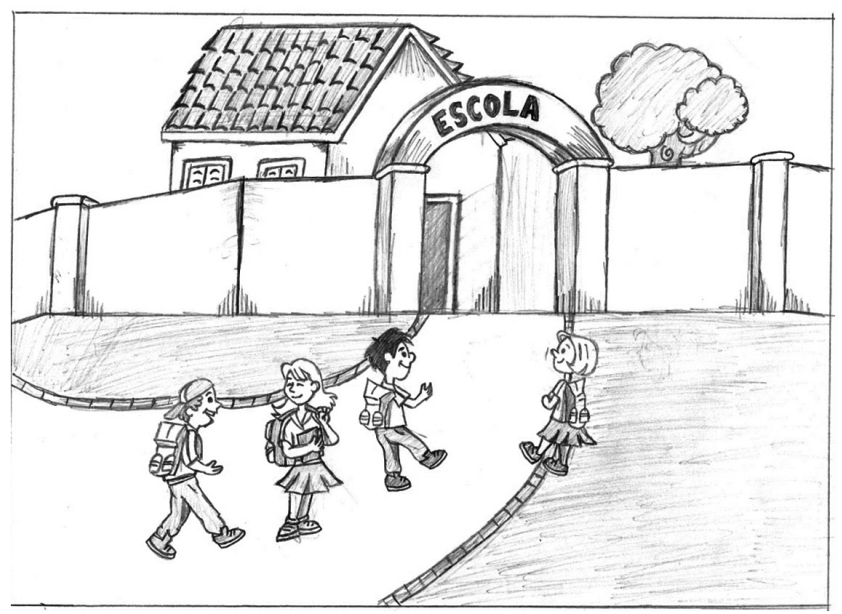

Figura 5. Direito à educação (conforme artigos $4^{\circ}$ e 53)
A entrevista foi realizada na própria escola dos participantes. Em sessão individual, gravada em áudio, cada participante foi solicitado a observar cada uma das cinco cenas previstas, uma de cada vez, e a emitir opiniões, realizando um reconhecimento do direito que cada cena lhe sugerisse. A pergunta básica, formulada pelo entrevistador, era: que direito a criança está tendo? Ao nomear a cena, em termos de direito atribuído ao protagonista, a criança efetuava o reconhecimento. Por exemplo, se ela respondia "direito de trabalhar", ainda assim, o entrevistador devolvia a resposta, em forma de pergunta (por exemplo: criança tem direito de trabalhar?), possibilitando uma melhor explicitação do reconhecimento e dos significados nele implicados. Diante de eventual hesitação do participante em efetuar o reconhecimento, o entrevistador solicitava que ele ou ela descrevesse o que estaria acontecendo na cena. Em seguida, perguntava sobre o direito. Por exemplo: se o participante respondia que a criança "está trabalhando", o entrevistador perguntava se "criança tem direito de trabalhar".

\section{Análise de Dados}

A expressão oral, gravada em áudio, foi transcrita e, em seguida, verificou-se se havia conexão entre a expressão da criança e o direito sugerido pela cena. A expressão da criança deveria incluir a nomeação do direito. Esta conexão foi o indicador de reconhecimento. A expressão do participante foi aceita como indicadora de reconhecimento mesmo quando era mais concreta do que a definição prévia do direito sugerido pela cena. Por exemplo: o direito à educação pode significar para um participante o direito de estudar e, para outro, o direito de ir à escola ou o direito de aprender. No momento seguinte, foram identificados os conhecimentos compartilhados (significados) pelos participantes de cada escola. E, por último, foram identificados os compartilhamentos entre os participantes das três escolas. Nesse processo, foram agregados os significados que, mesmo não sendo nucleares, isto é, mesmo não implicados na confluência de expressões dos participantes, aportavam informações esclarecedoras aos primeiros.

\section{Resultados e Discussão}

\section{Direito à Alimentação}

Todos os participantes reconhecem este direito, mas é interessante como eles marcam o "direito de tomar café", sugerindo a importância que conferem à primeira refeição do dia e como esta refeição é representada metonimicamente por essa bebida tão presente nos hábitos alimentares do brasileiro. A expressão assinalada acima aparece mais entre as crianças da escola pública rural (apresentada por quatro participantes) e aparece menos entre as crianças da escola particular urbana (apresentada por dois participantes). Di- 
ferentemente, cinco crianças da escola particular urbana utilizam o verbo "alimentar" ou o substantivo "alimentação" ("direito de se alimentar" ou "direito da alimentação"), enquanto que, ao invés disso, três crianças da escola pública rural preferem o verbo "comer" ("direito de comer"). As crianças da escola pública urbana apresentam tanto o "direito de comer" (dois participantes) quanto o "direito de se alimentar" (dois participantes).

Podemos depreender dessas indicações o seguinte: primeiro, é possível que as crianças da escola pública rural estejam a enfatizar a primeira refeição como expressão da importância de que essa refeição se reveste, nas áreas rurais, em função da jornada de trabalho cotidiana. Entre os sertanejos, o café é uma bebida sobejamente valorizada e, não raro, entre os mais pobres, o café com farinha de mandioca constitui a primeira refeição do dia. Segundo e, simultaneamente, as crianças da área rural usam conceitos mais concretos, mais colados à ação ("comer") do que o fazem as crianças da área urbana ("se alimentar" e "alimentação"). E, entre as crianças da área urbana, uma da escola particular utiliza um conceito ainda mais abstrato ("alimentação saudável"), o que remete, presumivelmente, ao trabalho da escola ou às interações em que essa criança se envolve em outros espaços sociais possibilitados por sua posição socioeconômica.

\section{Direito de Brincar}

Este direito também é reconhecido por todos os participantes. Porém, é curioso como as crianças da escola pública rural ficam presas à intransitividade do verbo brincar. Parece que, para elas, brincar é algo difuso e que, mesmo assim, não exige complemento ("direito de brincar"), por ser suficientemente claro. Entre as crianças da escola pública urbana, algo similar ocorre. Apenas uma das crianças sente necessidade de complementar, implicando as dimensões interativas e afetivas da experiência ("direito de se divertir, de brincar com outras crianças").

Quatro das crianças da escola particular urbana também se limitam à intransitividade do verbo brincar, mas três delas vão além. Uma indica o lugar ("direito de brincar no parque"), outra assinala a atividade e o brinquedo ("direito de brincar, jogar bola") e a terceira aponta a vivência subjetiva ("direito de brincar, se divertir"). Ao menos entre algumas das crianças da escola particular urbana a experiência de brincar parece constituir-se em uma atividade mais precisa, em um momento mais bem delimitado.

\section{Direito à Inviolabilidade da Integridade Física}

A preferência das crianças é, principalmente, pelo uso do verbo "apanhar" para se referir ao que acontece à criança na cena retratada no desenho. Elas realizam um contraponto entre a ação da mãe, que consiste em "bater", e a experiência de "apanhar", da criança. Apenas uma criança da escola pública urbana utiliza a expressão "ser maltratada" (que apre- senta um grau de abstração mais elevado) e duas crianças da escola pública rural utilizam a expressão "levar surra".

Quatro crianças da escola pública urbana, quatro da escola pública rural e apenas uma da escola particular reconhecem plenamente o direito à inviolabilidade da integridade física. Duas dessas crianças (a da escola particular e uma da escola pública rural) apontam o diálogo como estratégia adequada para suplantar a violência física. Duas outras dessas crianças da escola pública rural sugerem o "castigo" como alternativa menos danosa do que a violência física.

As outras crianças (seis da escola particular, três da escola pública urbana e três da escola pública rural) reconhecem o direito, mas com uma ressalva bastante genérica. Elas consideram que a criança pode sofrer violência física na relação parental "quando faz alguma coisa errada" ou "se tiver algum motivo". Portanto, o reconhecimento do direito se faz acompanhar de sua relativização. E, simultaneamente, aparece a noção da necessidade de disciplinar a criança em conformidade com um padrão moral, baseado na oposição entre o bem e o mal, entre o certo e o errado, e a crença de que esse disciplinamento necessita, às vezes, da sujeição do corpo ao sofrimento e do espírito ao medo.

\section{Proibição do Trabalho}

Quatro crianças (sendo uma da escola particular, uma da escola pública urbana e duas da escola pública rural), ao invés de reconhecerem a proibição do trabalho, expressam a presunção do direito de trabalhar. Para a criança da escola particular, há uma restrição: "não pode fazer trabalho pesado, mas trabalho leve pode". Há aqui uma prescrição relativa ao tipo de trabalho. Essa prescrição é baseada no reconhecimento de que fisicamente a criança é frágil, não pode ser equiparada ao adulto e de que o trabalho não pode sobrepujar suas forças. Uma das crianças da escola pública rural indica o trabalho como uma possibilidade de "ajudar" a mãe ou o pai e a outra condiciona esse direito a uma autorização, restringindo-o a alguns a quem "o pai e a mãe deixam" trabalhar. Portanto, essas crianças da área rural situam a problemática no mundo da casa, como algo dependente das necessidades e desígnios familiares.

Entre as crianças que reconhecem a proibição do trabalho, aquelas da escola pública rural justificam esse reconhecimento afirmando que "direito de trabalhar só quando crescer". Essas crianças focalizam prioritariamente o desenvolvimento físico como pré-requisito para o direito de trabalhar. Uma das crianças da escola particular também protela esse direito para a idade adulta, simplesmente, mas outras quatro apresentam um compartilhamento divergente, preferem apontar o que deve ser feito em lugar do trabaIho: "direito de brincar, estudar, ir pra escola". Para essas crianças, o trabalho deve ser precedido por um período de atividades preparatórias, realizadas na escola.

Sendo assim, não aparece, na fala dessas crianças, qualquer referência à possibilidade do trabalho na condição de aprendiz a partir de catorze anos de idade, 
conforme preconiza o Art. 60 do Estatuto da Criança e do Adolescente. Para elas, somente duas alternativas configuram-se como viáveis: o trabalho, ainda na infância, como ajuda na faina familiar ou o trabalho como efetiva inserção no mundo adulto.

\section{Direito à Educação}

Todas as crianças reconhecem este direito. Elas compartilham as noções de "ir pra escola" e de "estudar". Este "ir pra escola" sugere um entrelaçamento com o direito de liberdade e envolve a possibilidade do deslocamento entre a casa e a escola como um desejável exercício da autonomia.

Mas há, também, peculiaridades de cada escola. Três crianças da escola particular situam a escola como o lugar de aprender ("direito de ir pra escola aprender") e uma dessas crianças relaciona essa aprendizagem a uma preparação "para ter um futuro melhor", para o sucesso. Outra peculiaridade é apresentada por uma criança da escola pública urbana. Além do estudo, ela situa a escola como lugar de brincadeira e de convivência: "direito de ir pra escola estudar, brincar, fazer colegas". E nos perguntamos se esta escola já incorpora isto em sua prática. O educador precisa percorrer muitos caminhos, frequentemente, em sua prática e em seus estudos, até se deparar com a possibilidade que essa criança tão singelamente intui e expressa: a escola como um lugar da alegria, do saber e do estabelecimento de vínculos, simultaneamente.

A tradição cartesiana, que se traduz na escola como opção pelo cultivo de habilidades lógico-matemáticas e linguísticas, tem significado a negligência de outras dimensões constitutivas do processo educativo. Por conseguinte, sentimentos e emoções têm sido considerados como eventos incompatíveis com o exercício da racionalidade e, às vezes, francamente indesejáveis. Nessa perspectiva, a alegria e a brincadeira passaram a ter momentos pontuais, como contraponto para amenizar a "seriedade" dos estudos. E a dimensão relacional tornou-se um fator extrínseco que pode interferir positiva ou negativamente no processo de ensino-aprendizagem.

Essas formas de olhar, ao escamotear a percepção e as significações da totalidade do fenômeno educativo, para os educadores, promoveram algo como um ocultamento de dimensões mais estreitamente vinculadas ao exercício da sensibilidade. Sendo assim, torna-se bem mais fácil para a criança, com sua capacidade de deslumbramento diante do óbvio, poder, de modo singelo, apontar o dedo e dizer que "o rei está nu", como ocorre no conhecido conto de fadas.

\section{Conclusões}

Os direitos mais reconhecidos pelas crianças são: o direito à alimentação, o direito de brincar e o direito à educação. O reconhecimento da proibição do trabalho fica em segundo plano e o reconhecimento do direito à inviolabilidade da integridade física fica em terceiro plano.
O baixo reconhecimento do direito à inviolabilidade da integridade física parece indicar a prevalência do senso comum, até então, para essas crianças, como via de acesso predominante a esses conhecimentos que são compartilhados (significados) e que se manifestam mais frequentemente pelos conceitos espontâneos, conforme Vygotsky (2000). Segundo Salles (2005), as formas pelas quais os pais cuidam dos filhos estão entrelaçadas às concepções de infância vigentes na sociedade. Haveremos de convir, entretanto, que essas concepções não são homogêneas. Nos casos em estudo, parece haver indicações de concepções que se difundem somente pelo senso comum, sem qualquer participação sistemática da escola. Evidencia-se, pois, a sobrevivência e o predomínio de concepções mais antigas, anteriores ao Estatuto da Criança e do Adolescente. Essas concepções incrustam-se nas práticas sociais, constituindo o poder "naturalizante" da tradição. Dessa forma, persiste a violência na educação familiar da criança, frequentemente como "simples palmadas". E a criança, ela própria, aceita o fato como algo que faz parte da ordem natural das coisas.

No século XVI, no Brasil, o ensino das crianças índias, conduzido pelos jesuítas, era baseado num sistema disciplinar que incluía vigilância constante, delação e castigos corporais. O castigo corporal era normal, como afirma Chambouleyron (2004), e sabe-se que esse padrão sobreviveu na escola até o século $X X$. Entre os séculos $X V I$ e $\mathrm{XVIII}$, as crianças pequenas eram muito mimadas, tratadas como brinquedos. E isto era condenado pelos moralistas, que consideravam boa educação aquela baseada em castigos físicos e nas tradicionais palmadas. Na verdade, castigos e mimos coexistiam, de acordo com Del Priore (2004). Esse tratamento era dispensado, evidentemente, às crianças brancas. Góes e Florentino (2004) assinalam que, diferentemente, as crianças negras eram adestradas pela humilhação, pelo trabalho e pelos maus-tratos, de modo a se habituarem desde muito cedo à condição de escravas.

O baixo reconhecimento do direito à inviolabilidade da integridade física parece indicar, também, a precariedade da difusão do Estatuto da Criança e do Adolescente e o não envolvimento da escola neste processo. Sugere que as práticas educativas, no âmbito da família, utilizando o expediente da violência física, continuam na atualidade e que muitos pais não estão sendo alcançados e sensibilizados pelo Estatuto. Portanto, transcorridos dezoito anos da edição do Estatuto da Criança e do Adolescente, seu conteúdo ainda não é contemplado sistematicamente pelo trabalho das escolas em que estudam as crianças participantes deste estudo. Desse modo, sua difusão é falha justamente entre os indivíduos mais implicados nele: as próprias crianças. Essa falha decorre apenas da ausência (ou ineficiência) de políticas públicas ou, também, a escola resiste à inclusão da temática dos direitos da criança em seu cotidiano? Esta é uma questão importante que demanda estudo específico.

Os significados de infância que aparecem, nas expressões das crianças, entrelaçados às noções de direitos são: criança é um indivíduo em processo de desenvolvimento, que se alimenta, brinca e estuda. Além disso, a criança 
pode ser punida pelos pais, através de violência física ("surra"), "se fizer algo errado"; mas há alternativas à violência física que são preferíveis (diálogo ou "castigo"). A possibilidade de trabalhar existe, mas deve respeitar a condição do desenvolvimento físico da criança (sua fragilidade), depende de autorização de seus pais e da necessidade de ajuda que esses apresentem (para crianças da escola rural). Ou seja, é algo sobre o que se delibera e que se efetiva no âmbito familiar, no mundo da casa, e que reafirma a noção de dependência infantil, como assinala Salles (2005).

A ênfase no expediente da "ajuda" parece deslocar, desde logo (e mesmo que as crianças disso não tenham consciência), a questão do trabalho da rota da exploração, posicionando-a, no máximo, em processos de socialização baseados nas necessidades relativas à subsistência, que são mais característicos de famílias pobres e, presumivelmente, mais resistentes em famílias de áreas rurais. Não sendo assim, emerge a concepção de que a criança deve passar por uma preparação na escola (do ponto de vista das crianças da escola particular) ou deve esperar que seu crescimento físico a introduza no mundo adulto (para as crianças da escola rural).

Essa necessária preparação escolar nos lembra que, se no passado eram alijados sumariamente da escolarização, hoje os filhos dos pobres são privados de uma escolarização de qualidade, restando-lhes a alternativa de se tornarem "cidadãos úteis e produtivos", o que neutralizaria, supostamente, o "estigma da pobreza": "pobre, mas trabalhador", portanto, como assinalam Dourado, Dabat e Araújo (2004, p.412).

Cabe, a esta altura do relato, que abordemos uma limitação importante deste estudo. Demo-nos conta, desde o início, da reduzida quantidade de direitos focalizados, principalmente porque considerávamos a possibilidade de abstrair os significados de infância neles incorporados. A dificuldade que não conseguimos transpor foi a de representar em desenhos cenas que sugerissem claramente, sem dubiedade, o exercício ou a violação de outros direitos previstos pelo Estatuto da Criança e do Adolescente (Brasil, 1995). E resultou daí uma visão dos significados de infância certamente limitada, mas, ainda assim, bastante expressiva.

As crianças estão em plena sintonia com o Estatuto da Criança e do Adolescente (Brasil, 1995) em relação aos direitos que se articulam com os significados de infância mais difundidos e que são, em nossa cultura, definidores da criança (direito à alimentação, direito de brincar e direito à educação); significados amplamente compartilhados e, desde muito tempo, presentes na dimensão do senso comum. Os grupos sociais pelos quais transitam essas crianças são, afinal, a fonte desses significados que elas compartilham, conforme assinala Oliveira (1992), e aos quais conferem sentidos pessoais, em função de suas próprias vivências afetivas.

Mas, quanto à proibição do trabalho ou ao direito à inviolabilidade da integridade física, elas apresentam compartilhamentos divergentes, ancorados em sua posição socioeconômica, em suas necessidades, ou seja, em suas condições concretas de existência e no acesso aos conhecimentos circulantes que estas lhes possibilitam. De um lado, ainda é bastante recente, se não atual, a luta pela extinção efetiva da exploração do trabalho infantil. De outro lado, ainda é muito presente a violência doméstica contra crianças ou, no mínimo, o renitente uso das denominadas "palmadas educativas" no âmbito familiar.

Essas diferenças transparecem no pertencimento à escola particular (crianças oriundas de famílias que se situam em estratos sociais médios) ou às escolas públicas (crianças oriundas de famílias mais pobres). E dizem respeito, também, ao predomínio da dimensão rural ou urbana da experiência dessas crianças, em que pese a proximidade entre as áreas urbana e rural no município em pauta. Isto nos conduz a pensar, inevitavelmente, na existência de infâncias diversas no âmbito da população.

De todo modo, a exígua presença de conceitos científicos, conforme conceituação de Vygotsky (2000), nas expressões das crianças, parece indicar que os seus compartilhamentos divergentes mantêm alguma conexão não diretamente com o Estatuto da Criança e do Adolescente, mas com as transformações ou conservações que vêm ocorrendo nas práticas sociais relacionadas à infância. Essas transformações ou conservações ocorrem, provavelmente, sem homogeneidade, mas comportando tensões, contradições e conflitos, e mais facilmente no âmbito de alguns grupos e comunidades do que de outros. Em síntese, o novo não substitui o antigo, simplesmente, mas, de alguma forma, com ele convive. Lembrando o que afirma Miller (1996), os significados variam nos subgrupos, pois estes acessam os significados de modo diferenciado. E de modo diferenciado eles são objetivados em unidades sociais como famílias, escolas, comunidades ou grupos distinguidos pelo status socioeconômico.

Sendo assim, a exiguidade de conceitos científicos nas expressões das crianças não as impede de reconhecer os seus direitos. Os conceitos espontâneos dão conta disso. Se, de um lado, isso significa que elas não desenvolvem ainda um pensamento mais elaborado ou crítico sobre a questão, como podemos depreender a partir de Vygotsky (2000), de outro lado, significa que, mesmo assim, elas podem participar ativamente da construção coletiva de concepções e práticas sociais alternativas àquelas mais enraizadas na tradição.

\section{Referências}

Alvarenga, K., Julião, M., \& Silva, A. M. (1998). Crianças e adolescentes vítimas de exploração sexual. Em A. Diniz \& A. P. Lobo, A criança e o adolescente em situação de risco em debate (pp. 77-92). Rio de Janeiro: Litteris-KroArt.

Alves, J. M. (1993). Uma abordagem psicológica ao desenvolvimento inicial da fala sobre volição, afeto e cognição. Recuperado: 01 de mai. 2005, da Bireme (Centro Latino-Americano e do Caribe de Informação em Ciências da Saúde). Disponível: http://bases.bireme.br 
Ariès, P. (1981). História social da criança e da família (2a ed.). Rio de Janeiro: LTC.

Assis, S. G., \& Constantino, P. (2001). Filhas do mundo: infração juvenil feminina no Rio de Janeiro. Rio de Janeiro: FIOCRUZ. Recuperado: 05 mai. 2005. Disponível: http://bases.bireme.br

Bobbio, N. (1992). A era dos direitos. Rio de Janeiro: Campus.

Brasil. (1995). Estatuto da Criança e do Adolescente: Lei 8.069 de 13 de julho de 1990_(5a ed.). São Paulo: Peres.

Bronckart, J. P. (1999). Atividade de linguagem, textos e discurso: por um interacionismo sócio-discursivo. São Paulo: EDUC.

Chambouleyron, R. (2004). Jesuítas e as crianças no Brasil quinhentista. Em M. Del Priore (Org.), História das crianças no Brasil (4a ed.) (pp. 55-83). São Paulo: Contexto.

Cardoso, N. A. (1998). Educação e cidadania: as representações sociais de cidadania de jovens e participação em contexto comunitário de educação. Dissertação de mestrado, Universidade Federal de Goiás, Goiânia.

Chaves, A. M., Borrione, R. T. M., \& Mesquita, G. R. (2004). Significado de infância: a proteção à infância oferecida pela Santa Casa de Misericórdia na Bahia do século XIX. Interação em Psicologia, 8, 103-111.

Del Priore, M. (2004). O cotidiano da criança livre no Brasil entre a Colônia e o Império. Em M. Del Priore (Org.), Histórias das crianças no Brasil (4a ed.) (pp. 84-106). São Paulo: Contexto.

Domingues, J. M. (2002). Interpretando a modernidade: imaginário e instituições. Rio de Janeiro: FGV.

Dourado, A., Dabat, C., \& Araújo, T. C. (2004). Crianças e adolescentes nos canaviais de Pernambuco. Em M. Del Priori (Org.), História das crianças no Brasil (4a ed.) (pp. 407-436). São Paulo: Contexto.

Fiamenghi Junior, G. A., Bressan, C. G., \& Porto, J. C. (2003). O desenvolvimento da agressão entre crianças de pré-escola: subsídios para uma análise das relações sociais. Temas desenvolv., 12(67), 26-32.

Fiske, A. P., Kitayama, S., Markus, H. R., \& Nisbett, R. (1998). The cultural matrix of social psychology. Em D. T. Gilbert, S. T. Fiske \& G. Lindzey (Eds.), The handbook of social psychology (pp. 915981). New York: McGraw-Hill.

França Junior, I. (2003). Abuso sexual na infância: compreensão a partir da epidemiologia e dos direitos humanos. Interface comum saúde educ., 7(12), 23-38.

Gentili, P. (1995). Adeus à escola pública: a desordem neoliberal, a violência do mercado e o destino da educação das maiorias. Em
P. Gentili (Org.), Pedagogia da exclusão: crítica ao neoliberalismo em educação (pp. 228-252). Petrópolis, RJ: Vozes.

Góes, J. R. de, \& Florentino, M. (2004). Crianças escravas, crianças dos escravos. Em M. Del Priori (Org.), História das crianças no Brasil (4a ed.) (pp. 177-191). São Paulo: Contexto.

Hurtado, I. (2002). Percepciones y actitudes de los padres e madres de familia sobre el trabajo infantil y la educación. Manágua; UNICEF. Recuperado: 05 mai. 2005. Disponível: http://bases.bireme.br

Keller, H. (1998). Diferentes caminhos de socialização até a adolescência. Rev. bras. crescimento desenvolv. hum., 8(1/2), $1-14$.

Kramer, S. (2003). Infância, cultura contemporânea e educação contra a barbárie. Em L. C. Bazílio \& S. Kramer, Infância, educação e direitos humanos (pp. 83-106). São Paulo: Cortez.

Leontiev, A. N. (1978). O desenvolvimento do psiquismo. Lisboa: Livros Horizonte.

Luria, A. R. (1990). Desenvolvimento cognitivo: seus fundamentos culturais e sociais. (2a ed.) São Paulo: Ícone.

Marshall, T. H. (1967). Cidadania, classe social e status. Rio de Janeiro: Zahar.

Matos, F. L. A. de, Van der Put, M. C., \& Ferreira, L. M. T. (1998). Crianças e adolescentes e a dependência química. Em A. Diniz \& A. P. Lobo, A criança e o adolescente em situação de risco em debate (pp. 119-135). Rio de Janeiro: Litteris-KroArt.

Melchiori, L. E., \& Alves, Z. M. B. (2000). Comportamento de bebês em situações de separação e reencontro com os pais, na rotina diária da creche. Paideia, 10(18), 51-59.

(2000). Representações sociais de justiça em adolescentes infratores: discutindo novas possibilidades de pesquisa. Psicologia: Reflexão e Crítica, 13, 59-71.

Miller, J. G. (1996). Theoretical issues in cultural psychology. Em J. B. Berry e cols. (Eds.), Handbook of cross-cultural psychology (pp. 85-128). London: Allyn and Bacon.

Molinari, L. (2001). Social representations of children's rights: The point of view of adolescents. Swiss Journal of Psychology, 60(4), 231-243.

Molon, S. I. (2003). Subjetividade e constituição do sujeito em Vygotsky. Petrópolis, RJ: Vozes.

Oliveira, M. K. (1992). Vygotsky e o processo de formação de conceitos. Em Y. de La Taille, M. K. de Oliveira \& H. Dantas, Piaget, Vygotsky, Wallon: teorias psicogenéticas em discussão (pp. 2334). São Paulo: Summus. 
Pinheiro, A. A. A. (2004). A criança e o adolescente, representações sociais e processo constituinte. Psicologia em Estudo, 9(3), 343355.

Pinheiro, A. M. V. (1995). Dificuldades específicas de leitura: a identificação de déficits cognitivos e a abordagem do processamento de informação. Psicol. Teor. Pesqui., 11(2), 10715.

Salles, L. M. F. (2005). Infância e adolescência na sociedade contemporânea: alguns apontamentos. Estudos de Psicologia), 22, 33-41.
Teixeira, C. L. (2001). O outro lado do espelho: a exploração sexual sob o olhar de adolescentes prostituídas. Dissertação de mestrado, Pontifícia Universidade Católica de São Paulo, São Paulo.

UNICEF Brasil (2007). Convenção sobre os Direitos da Criança. Recuperado: 25 set. 2007. Disponível: http://www.unicef.org/ brazil/dir_cri.htm

Vygotsky, L. S. (2000). Pensamento e linguagem (2a ed.). São Paulo: Martins Fontes.

\section{Sobre os autores}

Gilberto Lima dos Santos (gilblimas@hotmail.com)

Universidade do Estado da Bahia, Salvador - BA

Antonio Marcos Chaves (amchaves@ufba.br)

Universidade Federal da Bahia, Salbador - BA

\section{Correspondência}

Gilberto Lima dos Santos

Rua Potiraguá, Qd 4 / L. 4, Jd. Brasília / Pernambués

CEP 41.100-160 - Salvador - BA. 